\title{
Assessment of apolipoprotein B/ apolipoprotein A-I ratio in non-ST segment elevation acute coronary syndrome patients
}

Haitham Galal ${ }^{*}$ D, Ayman Samir and Mohamed Shehata

\begin{abstract}
Background: The apolipoprotein B/apolipoprotein A-I ratio was shown to be strongly related to the risk of myocardial infarction in several large-scale studies. The current study aimed at exploring the diagnostic and shortterm prognostic values of apolipoprotein B/apolipoprotein A-I ratio in patients presenting with non-ST segment elevation acute coronary syndrome. One hundred patients with non-ST segment elevation acute coronary syndrome were prospectively enrolled, in addition to a matched group of 100 patients with chronic stable angina. Serum levels of total cholesterol, low-density lipoprotein, high-density lipoprotein, triglycerides, and apolipoproteins $\mathrm{B}$ and $\mathrm{A}-\mathrm{I}$ were quantified in both groups. Patients with non-ST segment elevation acute coronary syndrome underwent coronary angiography.

Results: The mean age of the study population was $57 \pm 6$ years, $65 \%$ being males. The non-ST segment elevation acute coronary syndrome group showed significantly unfavorable lipid profile parameters, including apolipoprotein B/apolipoprotein A-I ratio. Higher apolipoprotein B/apolipoprotein A-I ratio was associated with more coronaries showing significant stenosis and more complex lesion morphology. Receiver operating characteristic curve analysis reached an optimal cut-off value of 0.93 for diagnosis of non-ST segment elevation acute coronary syndrome (sensitivity $70 \%$ and specificity $88 \%$ ) and 0.82 for predicting the presence of multi-vessel disease (sensitivity $90 \%$ and specificity 97\%).
\end{abstract}

Conclusion: Apolipoprotein B/apolipoprotein A-I ratio is a useful tool of risk assessment in patients presenting with non-ST segment elevation acute coronary syndrome including prediction of coronary multivessel affection. Apolipoprotein B/apolipoprotein A-I ratio was shown to be strongly related to risk of myocardial infarction. Higher ratios of apolipoprotein B/apolipoprotein A-I were recorded in NSTE-ACS patients (versus stable angina patients). Higher apolipoprotein B/apolipoprotein A-I ratios were associated with more diseased coronaries and complex lesions. Apolipoprotein B/apolipoprotein A-I ratio is a useful tool for acute risk assessment in cardiac ischemic patients.

Keywords: Myocardial infarction, Coronary angiography, Lipoproteins

* Correspondence: haitham-w@hotmail.com

Department of Cardiology, Faculty of Medicine, Ain Shams University, Cairo,

Egypt

(C) The Author(s). 2020 Open Access This article is licensed under a Creative Commons Attribution 4.0 International License, which permits use, sharing, adaptation, distribution and reproduction in any medium or format, as long as you give appropriate credit to the original author(s) and the source, provide a link to the Creative Commons licence, and indicate if changes were made. The images or other third party material in this article are included in the article's Creative Commons licence, unless indicated otherwise in a credit line to the material. If material is not included in the article's Creative Commons licence and your intended use is not permitted by statutory regulation or exceeds the permitted use, you will need to obtain permission directly from the copyright holder. To view a copy of this licence, visit http://creativecommons.org/licenses/by/4.0/. 


\section{Background}

Apolipoproteins are proteins linked with lipids within lipoprotein particles. They are known to play essential roles in lipoprotein metabolism. They transfer these hydrophobic molecules in aqueous media of plasma directing lipids to their target organs, activating or inhibiting enzymes implicated in lipid metabolism [1]. Apolipoprotein A-I (apoA-I) is the largest ingredient of the high-density lipoprotein cholesterol (HDL-C) particle, constituting about $45 \%$ of its molecular mass [2]. Apolipoprotein B (apoB) exists in chylomicrons, e.g., apoB-48, and in very low-density lipoproteins cholesterol (VLDLC), intermediate density lipoprotein cholesterol, and low-density lipoprotein cholesterol (LDL-C) [3-5]. In several large-scale studies, the apoB/apoA-I ratio was related strongly to the risk of development of myocardial infarction and other cardiovascular diseases. Accumulating data suggest that apoB/apoA-I ratio could be a predictor of acute coronary syndromes in addition to the well-known elevated LDL-C and plasma total cholesterol/high-density lipoprotein cholesterol ratio as strong predictors of cardiovascular disease [6-9]. Direct assessment of the concentration of apoB was assumed to be superior in assessment of atherogenic dyslipidemia [10], and it is worth to mention that laboratory assessment of apolipoproteins is not affected by fasting status [11].

In the current study, the authors sought to determine the role of apoB/apoA-I ratio in risk assessment of development of non-ST segment elevation acute coronary syndrome (NSTE-ACS) in patients presented with acute typical chest pain. We also explored the short-term prognostic value of apoB/apoA-I ratio in NSTE-ACS patients meant for coronary angiography and subsequent revascularization.

\section{Methods}

\section{Study design and data collection}

A total of 100 patients presented with NSTE-ACS were enrolled on prospective basis. They were admitted to the coronary care unit $(\mathrm{CCU})$ within the first $6 \mathrm{~h}$ of onset of chest pain, in the period between December 2016 and February 2018. All the included patients met the clinical criteria of NSTE-ACS (acute coronary syndromes without ST segment elevation including unstable angina (UA) and non-ST segment elevation myocardial infarction (NSTEMI). NSTEMI is defined [12] by the rise and fall of cardiac biomarkers (preferably troponin) with at least one value above the 99th percentile upper reference limit and accompanied by one of the following: anginal chest pain, new ST segment/T-wave changes, development of pathologic $\mathrm{Q}$ waves on ECG, or imaging evidence of new regional wall motion abnormality. UA is defined by the presence of clinical symptoms of cardiac ischemia (new-onset typical chest pain, or change in typical anginal pattern, or development of angina at rest), with normal cardiac biomarkers of injury (troponin). ST segment depression or $\mathrm{T}$-wave inversions may be present in ECG.

Electrocardiographic assessment was performed on admission. A matched group of 100 patients with chronic stable angina was prospectively enrolled. The following patients were excluded: patients with prior history of acute coronary syndrome (ACS), with prior percutaneous coronary intervention, or coronary artery bypass graft surgery; patients with any myocardial disease other than ischemic; and those with history of lipid-lowering drug use (in NSTE-ACS group) or those on high intensity statins (for stable angina patients). Patients with contraindications for aspirin and/or clopidogrel use, limited life expectancy due to coexistent morbidities (e.g., malignancy), and chronic liver or kidney disease (serum creatinine $\geq 1.5 \mathrm{mg} / \mathrm{dl}$ or alanine aminotransferase and aspartate aminotransferase of $\geq 2$ times normal) were also excluded. Before enrollment, informed written consent was acquired from all patients and the study protocol was ratified by our local institutional human research committee, as it complies to the ethical guidelines of the Declaration of Helsinki quoted in 1975, as revised in 2008.

\section{Echocardiographic assessment}

Assessment of both segmental and global left ventricular systolic functions was performed by trans-thoracic echocardiography employing a GE Vivid 7 cardiac ultrasonic machine (GE, Horten, Norway). Standard 2D, M-mode, and Doppler images were acquired using a $2.5-\mathrm{MHz}$ phased array probe. Modified Simpson's method was used to assess left ventricular (LV) ejection fraction. LV internal dimensions using $\mathrm{M}$-mode and wall motion abnormalities were recorded. The standard 17-segment model was used to assess segmental wall motion abnormalities as applied by the American Society of Echocardiography [13]. Each segment was scored according to the grading system described by Knudsen et al. [14]. Views were acquired and analyzed upon CCU admission (in the NSTE-ACS group) by a single echocardiographer, who was blinded to the study protocol. Another blinded echocardiographer analyzed the views acquired for the chronic stable angina group.

\section{Laboratory work-up}

Venous sampling for cardiac troponin I was taken upon CCU admission for patients belonging to the NSTE-ACS group. Patients with initial negative cardiac troponin I results were subjected to serial measurements (every 12 h) for $48 \mathrm{~h}$. Plasma concentration of cardiac troponin I was measured using the Troponin I Ultra assay by Siemens ADVIA Centaur system (Siemens Diagnostics, 
Germany). Detection value was $6 \mathrm{pg} / \mathrm{mL}$, with a 99th percentile of $40 \mathrm{pg} / \mathrm{mL}$, and a coefficient of variation of $<10 \%$ at $30 \mathrm{pg} / \mathrm{mL}$. The serum levels of total cholesterol, LDL-C, HDL-C, and triglycerides (TG) were measured using standard methods. Fasting samples were withdrawn for chronic stable angina patients, while samples from the NSTE-ACS patients were withdrawn upon CCU admission (within $6 \mathrm{~h}$ of onset of chest pain). Serum apolipoprotein B and A-I levels were recorded using latex agglutination assays (Daiichi Pure Chemicals, Japan). The non-HDL-C concentration was calculated as the total cholesterol minus the HDL-C.

\section{Coronary angiography}

Patients belonging to the NSTE-ACS group underwent coronary angiography within the first $48 \mathrm{~h}$ after $\mathrm{CCU}$ admission. Vascular access was obtained through femoral artery puncture in all patients. Standard angiographic views were obtained. Subsequently, coronary revascularization strategies were tailored individually. Coronary angiographic data were interpreted by 2 independent operators, blinded to the study protocol. It included the number of vessels (epicardial vessels of $\geq 2.5 \mathrm{~mm}$ diameter) exhibiting significant luminal stenosis $(\geq 70 \%$ diameter reduction), maximum grading of luminal stenosis (percentage of diameter reduction), and worst morphologic lesion type (type $\mathrm{A}, \mathrm{B}$, or $\mathrm{C}$ ) defined according to the American College of Cardiology/American Heart Association (ACC/AHA) angiographic classification of coronary lesions [15].

\section{Statistical analysis}

The sample size was projected from the study of Krintus et al. [16], which evaluated the use of apoB/apoA-I ratio in order to enhance the process of assessment of the risk of ACS. Power of the test was set to $80 \%$. The confidence interval was set to be $95 \%$, and the margin of error was set to $5 \%$. Sample size was quoted to be 100 patients per group. All continuous variables were described as mean \pm standard deviation $( \pm \mathrm{SD})$. Categorical variables were described using absolute and relative (percentage) frequencies. Comparisons of continuous variables between the study groups were done using Student's $t$ test. For categorical data, Pearson's chi-square test was performed. Kappa $(k)$ statistics with the confidence interval was used to assess inter-rater reliability $(k$ was 0.95). ANOVA test was used to estimate the relationship between apoB/apoA-I ratio and each of the number of significantly diseased coronaries and worst atherosclerotic lesion type. $P$ value was used to describe significance $(P \leq 0.05$ is significant value, $P \leq 0.01$ is considered highly significant value, and $P \geq 0.05$ is a nonsignificant result). ROC curve (receiver operating characteristic curve) was used to obtain the optimal cut-off value of ApoB/ApoA-I ratio in order to predict the presence of significant $\geq 2$ vessel disease in NSTE-ACS patients. Statistical calculations were done employing the Statistical Package for Social Sciences (SPSS for Windows) software (version 15.0, SPSS Inc., Chicago, USA).

\section{Results}

\section{Baseline characteristics}

A total of 200 patients were subjected to the study protocol. The mean age of the whole study cohort was $57 \pm 6$ years, $130(65 \%)$ being male patients. Both study groups were matched regarding age, gender, and risk factor of coronary artery disease. Forty-five (45\%) patients among the NSTE-ACS group were finally diagnosed as non-ST segment elevation myocardial infarction. There was no recorded significant difference between both study groups regarding echocardiographic data, body mass index, and pre-enrollment medications (Table 1).

\section{Blood work}

Data analysis showed that the NSTE-ACS group exhibited significantly higher total cholesterol, LDL-C, nonHDL-C, TG, total cholesterol/HDL-C, LDL-C/HDL-C, TG/HDL-C, and apoB and apoB/apoA-I values. However, the chronic stable angina group showed significantly higher HDL-C and apoA-I values (Table 2).

Among the NSTE-ACS patients, apoB/apoA-I ratio showed a significant positive correlation with total cholesterol $(r=0.477, P=0.016)$, LDL-C $(r=0.596, P=$ $0.002)$, non-HDL-C $(r=0.577, P=0.003)$, total cholesterol/HDL-C $(r=0.389, P=0.025)$, and LDL-C/HDL-C $(r=0.554, P=0.004)$. ApoB/apoA-I ratio among chronic stable angina patients showed weaker (less significant) positive correlations with the same parameters as follows: total cholesterol $(r=0.357, P=0.045)$, LDL-C $(r=$ $0.457, P=0.015)$, non-HDL-C $(r=0.389, P=0.025)$, total cholesterol/HDL-C $(r=0.377, P=0.035)$, and LDL-C/HDL-C ( $r=0.457, P=0.015)$. ApoB/apoA-I ratio did not show any statistically significant correlation with age, echocardiographic parameters, HDL-C, TG, and TG/HDL-C, in both study groups.

\section{Coronary angiography}

Only 85 (85\%) patients (NSTE-ACS group) showed angiographically significant coronary artery disease. Angiographic data were interpreted by 2 interventional cardiologists, who were not informed about the study protocol. Analysis of inter-observer variability revealed a close correlation between repeated interpretations, with a correlation coefficient of $r=0.95$.

Patients in the NSTE-ACS group were sub-classified according to number of coronary vessels (one vessel, two vessels, and $>2$ vessels) showing significant stenosis. Using ANOVA test, it was found that there was a 
Table 1 Baseline characteristics of the two study groups

\begin{tabular}{|c|c|c|c|}
\hline Variable & NSTE-ACS (no. = 100) & CSA (no. = 100) & $P$ value* \\
\hline Age,(years) & $59 \pm 6$ & $58 \pm 5$ & 0.601 \\
\hline Males & $66(66)$ & $64(64)$ & 0.598 \\
\hline Hypertension & $55(55)$ & $51(51)$ & 0.544 \\
\hline Diabetes mellitus & $30(30)$ & $32(32)$ & 0.598 \\
\hline Dyslipidemia & $58(58)$ & $56(56)$ & 0.568 \\
\hline Smoking & $37(37)$ & $40(40)$ & 0.696 \\
\hline Family history of CAD & $17(17)$ & $18(18)$ & 0.589 \\
\hline Body mass index (kg/m²) & $25 \pm 2$ & $26 \pm 3$ & 0.654 \\
\hline Left ventricle ejection fraction (\%) & $51 \pm 5$ & $54 \pm 3$ & 0.543 \\
\hline Left ventricle end diastolic diameter (mm) & $56 \pm 4$ & $53 \pm 4$ & 0.435 \\
\hline Left ventricle end systolic diameter (mm) & $39 \pm 3$ & $37 \pm 5$ & 0.556 \\
\hline Wall motion score index & $1.45 \pm 0.3$ & $1.42 \pm 0.22$ & 0.476 \\
\hline \multicolumn{4}{|l|}{ Pre-enrollment medications } \\
\hline Beta blockers & $12(20)$ & $14(24)$ & 0.589 \\
\hline Calcium antagonists & $11(18)$ & $9(16)$ & 0.597 \\
\hline Angiotensin converting enzyme inhibitors/angiotensin receptor blockers & $18(30)$ & $17(29)$ & 0.644 \\
\hline Oral nitrates & $13(22)$ & $12(21)$ & 0.688 \\
\hline
\end{tabular}

Categorical variables are presented as number (percentage)

Continuous variables are presented as mean \pm standard deviation

CAD coronary artery disease, CSA chronic stable angina, NSTE-ACS non-ST segment elevation acute coronary syndrome

*Pearson's chi-square and Student's $t$ tests

significant difference between the three sub-populations regarding mean apoB/apoA-I ratio $(P=0.02)$. Higher mean apoB/apoA-I ratio was significantly associated with more coronary arteries affection. Patients were reclassified according to frequency of presence of worst type of coronary lesions (lesion type A, B, or C). Using ANOVA test, it was found that there was a significant difference between the three sub-populations regarding mean apoB/apoA-I ratio $(P=0.03)$. Higher mean apoB/
apoA-I ratio was significantly associated with more complex lesion morphology (Table 3), and this was justified by a post hoc analysis test revealing that any group with higher apoB/A-I ratio was more significant than the other with lower apoB/A-I ratio. Patients were further reclassified according to maximum degree of luminal stenosis ( 70 to $<80 \%, 80$ to $<90 \%, 90$ to $<100 \%, 100 \%$ ). There was no statistically significant correlation between recorded apoB/apoA-I ratio and degree of angiographically

Table $\mathbf{2}$ Lipid profile indices of the two study groups

\begin{tabular}{llll}
\hline Variable & NSTE-ACS (no. = 100) & CSA (no. = 100) & $P$ value \\
\hline Total cholesterol $(\mathrm{mg} / \mathrm{dl})$ & $195 \pm 31.2$ & $183.3 \pm 31.2$ & $\mathbf{0 . 0 2 5}$ \\
Serum LDL cholesterol $(\mathrm{mg} / \mathrm{dl})$ & $124.8 \pm 19.5$ & $105.3 \pm 23.4$ & $\mathbf{0 . 0 3}$ \\
Serum HDL cholesterol $(\mathrm{mg} / \mathrm{dl})$ & $39 \pm 15.6$ & $50.7 \pm 11.7$ & $\mathbf{0 . 0 3}$ \\
Non-HDL-C $(\mathrm{mg} / \mathrm{dl})$ & $156 \pm 7.8$ & $132.6 \pm 19.5$ & $\mathbf{0 . 0 0 2}$ \\
Serum triglycerides $(\mathrm{mg} / \mathrm{dl})$ & $115.7 \pm 26.7$ & $89 \pm 17.8$ & $\mathbf{0 . 0 0 2}$ \\
Total cholesterol/HDL cholesterol & $5 \pm 2$ & $4 \pm 1.6$ & $\mathbf{0 . 0 0 3}$ \\
Triglycerides/HDL cholesterol & $1.3 \pm 0.8$ & $0.8 \pm 0.7$ & $\mathbf{0 . 0 0 0 6}$ \\
LDL cholesterol/HDL cholesterol & $3.2 \pm 1.3$ & $2 \pm 1.5$ & $\mathbf{0 . 0 0 0 5}$ \\
Apolipoprotein B (g/L) & $1.6 \pm 0.3$ & $1 \pm 0.02$ & $\mathbf{0 . 0 0 2}$ \\
Apolipoprotein A-I (g/L) & $0.9 \pm 0.2$ & $1.3 \pm 0.2$ & $\mathbf{0 . 0 0 2}$ \\
Apolipoprotein B/apolipoprotein A-l & $1.7 \pm 0.2$ & $0.7 \pm 0.1$ & $\mathbf{0 . 0 0 0 2}$ \\
\hline All vala
\end{tabular}

All variables are presented as mean \pm standard deviation $H D L$ high-density lipoprotein, $L D L$ low-density lipoprotein *Student's $t$ test 
Table 3 Mean ApoB/Apo A-I ratio in relation to the number of significantly diseased coronaries and type of coronary lesions in NSTE-ACS group

\begin{tabular}{|c|c|c|c|c|c|}
\hline Sub-population & & Number of patients ${ }^{\dagger}$ & Apolipoprotein B/apolipoprotein A- $\left.\right|^{\ddagger}$ & $F^{*}$ & $P$ value \\
\hline \multirow[t]{3}{*}{ Number of significantly diseased vessels } & 1 & $53(53)$ & $1.6 \pm 0.02$ & 737.7 & 0.02 \\
\hline & 2 & $20(20)$ & $1.8 \pm 0.04$ & & \\
\hline & $>2$ & $12(12)$ & $1.9 \pm 0.04$ & & \\
\hline \multirow[t]{3}{*}{ Type of worst lesion } & A & $48(48)$ & $1.6 \pm 0.04$ & 3.8 & 0.03 \\
\hline & B & $23(23)$ & $1.8 \pm 0.07$ & & \\
\hline & C & $14(14)$ & $1.9 \pm 0.07$ & & \\
\hline
\end{tabular}

*ANOVA test

'Variables are presented as number (percentage)

₹Variables are presented as mean \pm standard deviation (SD)

determined maximum luminal stenosis (Pearson's correlation coefficient, $0.154 ; P=0.07$ ) (Table 4).

Receiver operating characteristic curve analysis (Fig. 1) of apoB/apoA-I ratios among the NSTE-ACS patients showing significant coronary artery disease revealed that a cut-off value of $\geq 0.82$ predicted the presence of $\geq 2$ vessel disease, with sensitivity of $90 \%$, specificity of $97 \%$, positive predictive value of $88 \%$, negative predictive value of $99 \%$, and predictive accuracy of $98 \%$ (area under the curve $=0.97,95 \% \mathrm{CI} 0.782-0.973$ ). It may be worth to mention that the receiver operating characteristic curve analysis reached an optimal cut-off value of 0.93 for diagnosis of non-ST segment elevation acute coronary syndrome (sensitivity $70 \%$ and specificity $88 \%$ ), and of course, this needs a large-scale study population to reveal the proper diagnostic ability of the apoB/A ratio in the NSTE-ACS population.

\section{Discussion}

The current study presents 2 different roles for apoB/ apoA-I ratio in NSTE-ACS patients. The first one can be described as a tool of risk assessment of development of NSTE-ACS in patients presenting with acute typical chest pain. The other one presents a short-term prognostic tool in NSTE-ACS patients undergoing coronary angiography in terms of multivessel affection and lesion morphology which subsequently could affect the revascularization outcome. One of the well-known risk factors in ischemic patients is elevated level of LDL-C. Despite several studies indicating the necessity for LDL$\mathrm{C}$ recording in patients at risk of ACS development, centering only on LDL-C is not suggested as an ideal diagnostic and/or therapeutic approach [17]. The coexistence of high TG and low HDL-C, called atherogenic dyslipidemia, is linked to high apoB concentration, and as the role of apolipoproteins in coronary risk estimation is still debatable, the apoB/apoA-I ratio is considered a rising star predictor factor [18]. The results of both AMORIS and INTERHEART studies showed that the apoB/apoA-I ratio was the most powerful predictor of myocardial infarction among all investigated parameters and importantly, like C-reactive protein, was able to detect subjects at higher risk even when LDL-C values were normal $[5,8]$. In the current study, patients presented with NSTE-ACS showed unfavorable conventional lipid profile parameters, as compared with chronic stable angina patients. Moreover, they showed higher apoB and apoB/apoA-I ratio. These significant differences were recorded although both groups of included patients showed a comparable risk factor profile and were statin naïve. This could be solely attributed to the pathophysiologic nature of ACSs, including the inflammatory milieu. The authors sought to highlight the role of apoB/apoA-I ratio in risk assessment by estimating a cut-off value of 0.93 , predicting the diagnosis of NSTEACS. Previous trials had reported that an apoB/apoA-I ratio of $\geq 0.9$ is associated with increased risk of myocardial infarction $[5,8]$. This cut-off value was obtained through follow-up of patients with considerable risk of coronary artery disease. The current study reported the same cut-off value. However, blood samples were withdrawn at time of presentation to CCU (within $6 \mathrm{~h}$ of

Table 4 Mean ApoB/ApoA-I ratio in relation to maximum coronary luminal stenosis in the NSTE-ACS group

\begin{tabular}{lllll}
\hline Sub-population & & Number of patients* & Apolipoprotein B/apolipoprotein A-I ${ }^{\dagger}$ & $P$ value \\
\hline Percentage of luminal stenosis (\%) & 70 to $<80$ & $24(34)$ & $1.7 \pm 0.03$ & $\mathbf{0 . 7}(r=0.154)$ \\
& 80 to $<90$ & $36(36)$ & $1.8 \pm 0.04$ & $1.8 \pm 0.06$ \\
& 90 to $<100$ & $18(18)$ & $7(7)$ & $1.7 \pm 0.05$ \\
\hline
\end{tabular}

$r$ Pearson's correlation coefficient

*Variables are presented as number (percentage)

+Variables are presented as mean \pm standard deviation (SD) 


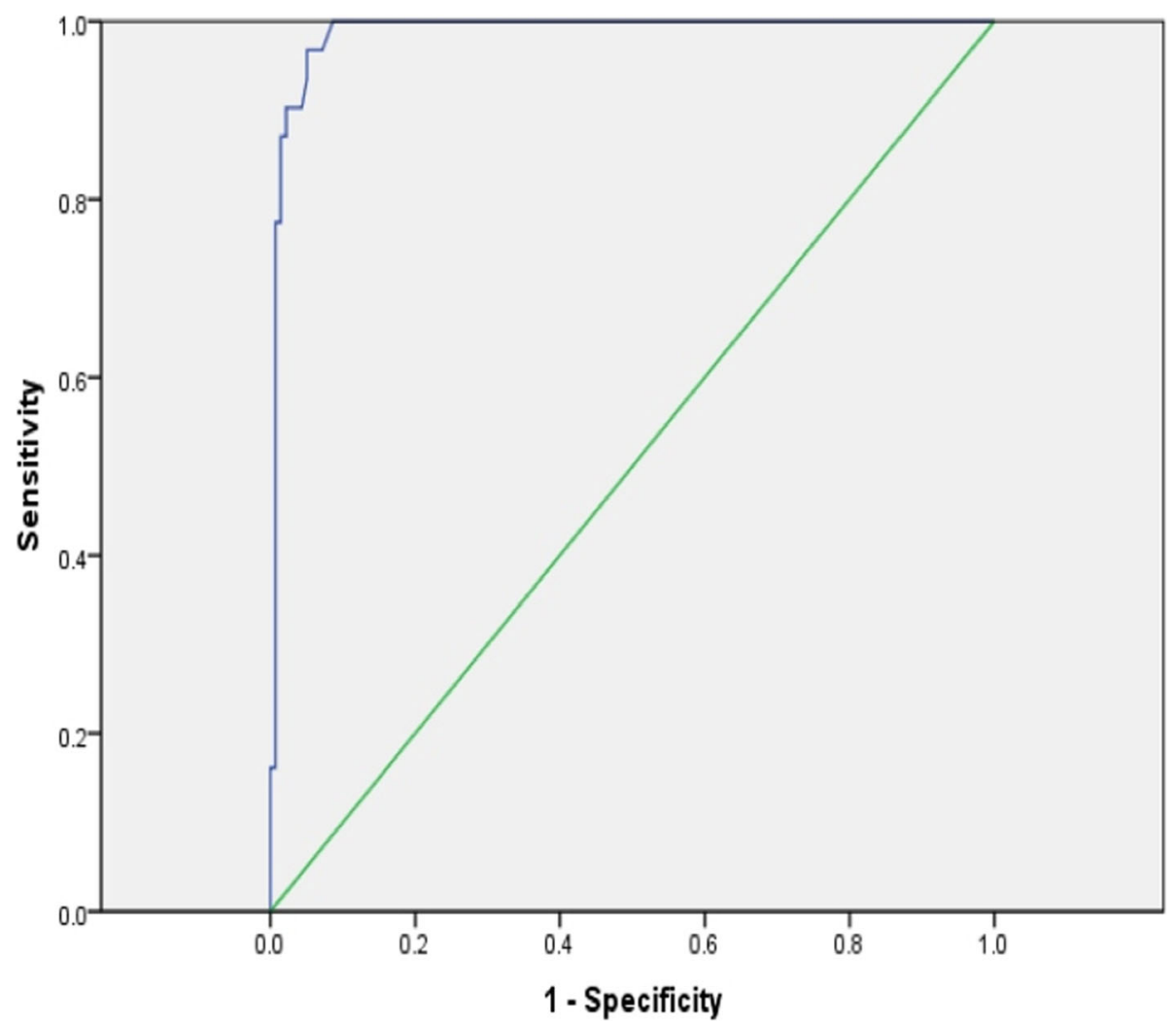

Fig. 1 Receiver operating characteristic (ROC) curve plotted to obtain the optimal cut-off value of ApoB/ApoA-I ratio in order to predict the presence of significant $\geq 2$ vessel disease in NSTE-ACS patients

acute chest pain), giving apoB/apoA-I ratio an additional diagnostic impact and confirming the results obtained by previous studies. Considering the cut-off point of this reliably measured ratio could provide a promising short-term prognostic tool in this clinical setting, when compared with conventional lipid profile parameters. Apolipoproteins are measured directly through accurate and internationally validated methods [19], by using a common reference method for apoA-I and apoB which is not obtainable for measurements of HDL-C and LDL-C, and without the interference of high TG levels [20]. Plasma apolipoprotein levels are mildly affected by biological variables, whereas plasma lipid levels vary in response to different metabolic factors [4]. Therefore, the measurements of apolipoproteins B and A-I can be done with no need of prior fasting $[7,21]$. These facts add more to the advantageous assessment of apoB/apoA-I ratio.

If the total apoB reflects the possibly atherogenic lipoproteins and apoA-I transports the major antiatherogenic HDL particles, the apoB/apoA-I ratio could reasonably provide a measure of the gross cholesterol balance [22]. That was evident in the current study through the positive correlation between apoB/apoA-I ratio and each of total cholesterol, LDL-C, non-HDL-C, total cholesterol/HDL-C, and LDL-C/HDL-C, which was more pronounced in NSTE-ACS patients. While some studies showed the usefulness of increased apoB levels as predictors of cardiac risk [23, 24], others have attributed this risk to reduced apoA-I levels [25]. However, the consensus in the literature showed that the ratio between atherogenic and anti-atherogenic particles, reflected by the apoB/apoA-I ratio, represents an additional and important parameter for cardiovascular risk prediction [26]. We excluded patients on statin therapy to avoid confounding factors. Multiple studies involving the apoB/apoA-I ratio revealed that lipid-lowering drugs, especially statins, have significant effects on the apolipoproteins levels [27-30].

The present study uniquely reported the relationship between apoB/apoA-I ratio and coronary angiographic features in NSTE-ACS patients. Higher apoB/apoA-I ratios were associated with more coronary arteries showing angiographically significant coronary artery disease and more lesion complexity. However, there was no significant correlation between apoB/apoA-I ratio and degree of luminal stenosis. We propose that NSTE-ACS is a setting of enhanced oxidative stress and elevated lipoprotein levels, conferring a pronounced pro-inflammatory thrombogenic 
milieu. On the other hand, a study by Tsimikas et al. reported a positive correlation between apolipoproteins and degree of coronary luminal stenosis [31]. They showed that plasma levels of oxidized phospholipids present on apoB-100-containing lipoproteins reflect the presence and extent of angiographically documented coronary artery disease. However, their study was conducted on stable ischemic patients.

The results of the current study have their assumed clinical implications. High apoB/apoA-I ratio $(\geq 0.82)$ recorded before coronary angiography in NSTE-ACS patients calls for proper readiness (pharmacological and technical) due to high probability of tackling a complex multi-vessel disease. This additionally implies the presence of an experienced interventionalist. Thus, apoB/ apoA-I ratio could help risk stratification of NSTE-ACS patients upon CCU admission. These patients are expected to have unfavorable angiographic outcomes, in spite of initial and/or persistent negative troponin results. The current study reached a cut-off value of 0.93 for apoB/apoA-I ratio that predicted the final diagnosis of NSTE-ACS. This could be of special importance in patients with initial negative troponin results. This population of patients should be regarded as a high-risk category among ACS patients. Moreover, this could have an impact on pharmacological treatment in CCU.

\section{Limitations of the study}

The concluded data presented in this study only apply for patients designated by inclusion and exclusion standards. This is a single-center study with a relatively small sample size. Serial sampling for apoB/apoA-I ratio, especially after coronary revascularization, was not included in the study protocol. Furthermore, follow-up of adverse cardiovascular events was also not included. Further multi-center studies with wider scope are needed for evaluation of long-term impact of high apoB/apoA-I ratio in revascularized NSTE-ACS patients.

\section{Conclusions}

ApoB/apoA-I ratio is a useful tool for risk assessment in patients presenting with acute typical chest pain. High apoB/apoA-I ratio predicts multi-vessel (cut-off value of 0.82 ) coronary artery disease with complex lesion morphology.

\begin{abstract}
Abbreviations
NSTE-ACS: Non-ST segment elevation acute coronary syndrome; ApoB/ ApoA: Apolipoprotein B/apolipoprotein A; HDL-C: High-density lipoprotein cholesterol; LDL-C: Low-density lipoprotein cholesterol; CCU: Coronary care unit; ACC/AHA: American College of Cardiology/American Heart Association
\end{abstract}

\section{Acknowledgements}

The authors like to express their gratitude for medical, technical, and nursing staff of cardiac catheterization, echocardiography, and blood work laboratories, for their cooperation to accomplish this work.

\section{Authors' contributions}

HG: Designed research, collected material and data from patients and wrote the paper. AS: Designed research, supervised the assays. MS: Designed research, collected material and data from patients and wrote the paper. All authors read and approved the final manuscript.

\section{Funding}

We did not receive any specific fund to cover this research

\section{Availability of data and materials}

The datasets used and analyzed during the current study are available from the corresponding author on reasonable request.

\section{Ethics approval and consent to participate}

The study was approved by the Research Ethics Committee (Faculty of Medicine, Ain Shams University, FWA 00006444), and all patients signed an informed consent for participation in the study in accordance with the Declaration of Helsinki.

\section{Consent for publication}

Not applicable

\section{Competing interests}

The authors have no conflicts of interest.

Received: 11 December 2019 Accepted: 27 April 2020

Published online: 24 May 2020

\section{References}

1. Beisiegel U (1998) Lipoprotein metabolism. Eur Heart J 19(Suppl A):S20-S23

2. Frank PG, Marcel YL (2000) Apolipoprotein A-l: structure-function relationships. J Lipid Res 41:853-872

3. Packard CJ, Shepherd J (1997) Lipoprotein heterogeneity and apolipoprotein B metabolism. Arterioscler Thromb Vasc Biol 17:3542-3556

4. Rifai N, Bachorik PS, Alberts JJ (1999) Lipids, lipoproteins, and apolipoproteins. In: Burtis CA, Ashwood ER (eds) Tietz - textbook of clinical chemistry, 3rd edn. Saunders, Philadelphia, pp 809-861

5. Walldius G, Jungner I (2006) The apoB/apoA-I ratio: a strong, new risk factor for cardiovascular disease and a target for lipid-lowering therapy - a review of the evidence. J Intern Med 259:493-519

6. McQueen MJ, Hawken S, Wang X, INTERHEART Study Investigators (2008) Lipids, lipoproteins, and apolipoproteins as risk markers of myocardial infarction in 52 countries (the INTERHEART study): a case-control study. Lancet 372:224-233

7. Walldius G, Jungner I, Holme I, Aastveit AH, Kolar W, Steiner E (2001) High apolipoprotein B, low apolipoprotein A-I, and improvement in the prediction of fatal myocardial infarction (AMORIS study): a prospective study. Lancet 358:2026-2033

8. Yusuf S, Hawken S, Ounpuu S, Dans T, Avezum A, Lanas F, McQueen M, Budaj A, Pais P, Varigos J, Lisheng L, INTERHEART Study Investigators (2004) Effect of potentially modifiable risk factors associated with myocardial infarction in 52 countries (the INTERHEART study): case-control study. Lancet 364:937-952

9. Emerging Risk Factors Collaboration, Di Angelantonio E, Sarwar N, Perry P, Kaptoge S, Ray KK, Thompson A, Wood AM, Lewington S, Sattar N, Packard CJ, Collins R, Thompson SG, Danesh J (2009) Major lipids, apolipoproteins, and risk of vascular disease. JAMA 302:1993-2000

10. Sniderman $A D$, Furberg $C D$, Keech $A$, Roeters van Lennep JE, Frohlich J, Jungner I, Walldius G (2003) Apolipoproteins versus lipids as indices of coronary risk and as targets for statin treatment. Lancet 361:777-780

11. Pfohl M, Schreiber I, Liebich HM, Häring HU, Hoffmeister HM (1999) Upregulation of cholesterol synthesis after acute myocardial infarction-is cholesterol a positive acute phase reactant? Atherosclerosis 142:389-393

12. Anderson JL, Adams CD, Antman EM et al (2013) for American College of Cardiology Foundation/American Heart Association Task Force on Practice Guidelines. 2012 ACCF/AHA focused update incorporated into the ACCF/ AHA 2007 guidelines for the management of patients with unstable angina/non-ST-elevation myocardial infarction: a report of the American College of Cardiology Foundation/American Heart Association Task Force on Practice Guidelines. Circulation. 127(23):e663-e828 
13. American Heart Association Writing Group on Myocardial Segmentation and Registration for Cardiac Imaging (2002) Standardized myocardial segmentation and nomenclature for tomographic imaging of the heart: a statement for healthcare professionals from the Cardiac Imaging Committee of the Council on Clinical Cardiology of the American Heart Association. Circulation 105:539-542

14. Knudsen AS, Darwish AZ, NØrgaard A, Gøtzsche O, Thygesen K (1998) Time course of myocardial viability after acute myocardial infarction: an echocardiographic study. Am Heart J 135:51-57

15. Smith SC Jr, Dove JT, Jacobs AK, Kennedy JW, Kereiakes D, Kern MJ, et al. ACC/AHA guidelines for percutaneous coronary intervention (revision of the 1993 PTCA guidelines)-executive summary: a report of the American College of Cardiology/American Heart Association task force on practice guidelines (Committee to revise the 1993 guidelines for percutaneous transluminal coronary angioplasty) endorsed by the Society for Cardiac Angiography and Interventions. Circulation. 2001; 103:3019-41.

16. Krintus M, Kozinski M, Stefanska A, Sawicki M, Obonska K, Fabiszak T, Kubica J, Sypniewska G (2012) Value of C-reactive protein as a risk factor for acute coronary syndrome: a comparison with apolipoprotein concentrations and lipid profile. Mediators Inflamm 2012:419804

17. Vaverkova H, Karasek D, Novotny D, Jackuliakova D, Lukes J, Halenka M, Frohlich J (2009) Apolipoprotein B versus LDL-cholesterol: association with other risk factors for atherosclerosis. Clin Biochem 42:1246-1251

18. Sypniewska G, Bergmann K, Krintus M. How do apolipoproteins ApoB and ApoA-I perform in patients with acute coronary syndromes. Journal of Medical Biochemistry De Gruyter Open Sp. z 0.o.; 30(3). Available from: https://doi.org/10.2478/v10011-011-0022-6.

19. Marcovina SM, Alberts JJ, Henderson LO, Hannon WH (1993) International Federation of Clinical Chemistry standardization project for measurements of apolipoproteins A-I and B. III. Comparability of apolipoprotein A-I values by use of international reference material. Clin Chem 39:773-781

20. Marcovina S, Packard J (2006) Measurement and meaning of apolipoprotein Al and apolipoprotein B plasma levels. J Intern Med 259:437-446

21. Talmud PJ, Hawe E, Miller GJ, Humphries SE (2002) Nonfasting apolipoprotein B and triglyceride levels as a useful predictor of coronary heart disease risk in middle-aged UK men. Arterioscler Thromb Vasc Biol 22: 1918-1923

22. Tani S, Nagao K, Anazawa T, Kawamata H, Furuya S, Takahashi H, lida K, Matsumoto M, Washio T, Kumabe N, Hirayama A (2010) Relation of change in apolipoprotein B/apolipoprotein A-I ratio to coronary plaque regression after Pravastatin treatment in patients with coronary artery disease. Am J Cardiol 105:144-148

23. Meisinger C, Loewel H, Mraz W, Koenig W (2005) Prognostic value of apolipoprotein $B$ and $A-1$ in the prediction of myocardial infarction in middle-aged men and women: results from the MONICA/KORA Augsburg cohort study. Eur Heart J 26:271-278

24. Westerveld HT, van Lennep JE, van Lennep HW, Liem AH, de Boo JA, van der Schouw YT, Erkelens DW (1998) Apolipoprotein B and coronary artery disease in women: a cross-sectional study in women undergoing their first coronary angiography. Arterioscler Thromb Vasc Biol 18:1101-1107

25. Luc G, Bard JM, Ferrières J, Evans A, Amouyel P, Arveiler D, Fruchart JC, Ducimetière P (2002) Value of HDL cholesterol, apolipoprotein A-I, lipoprotein A-I, and lipoprotein A-I/A-II in prediction of coronary heart disease. The PRIME Study. Arterioscler Thromb Vasc Biol 22:1155-1161

26. Walldius $G$, Jungner I, Aastveit AH, Holme I, Furberg CD, Sniderman AD (2004) The apoB/apoA-I ratio is better than cholesterol ratios to estimate the balance between plasma proatherogenic and antiatherogenic lipoproteins and to predict coronary risk. Clin Chem Lab Med 42:1355-1363

27. Walldius G, Jungner I (2004) Apolipoprotein B and apolipoprotein A-l: risk indicators of coronary heart disease and targets for lipid-modifying therapy. J Intern Med 255:188-205

28. Ballantyne CM, Andrews TC, Kramer JH, ACCESS study Group Atorvastatin Comparative cholesterol Efficacy and Safety Study. Correlation of non-highdensity lipoprotein cholesterol with apolipoprotein B: effect of 5 hydroxymethylglutaryl coenzime A reductase inhibitors on non-highdensity lipoprotein cholesterol levels. Am J Cardiol 2001; 88: 265-269.

29. Endreas M (2005) Statins and stroke. J Cereb Blood Flow Metab 25:1093-1110

30. Charlton-Menys V, Durrington P (2006) Apolipoproteins Al and B as therapeutic targets. J Intern Med 259:462-472
31. Tsimikas S, Brilakis ES, Miller ER, McConnell JP, Lennon RJ, Kornman KS, Witztum JL, Berger PB (2005) Oxidized phospholipids, Lp(a) lipoprotein, and coronary artery disease. N Engl J Med 353:46-57

\section{Publisher's Note}

Springer Nature remains neutral with regard to jurisdictional claims in published maps and institutional affiliations.

\section{Submit your manuscript to a SpringerOpen ${ }^{\circ}$ journal and benefit from:}

- Convenient online submission

- Rigorous peer review

- Open access: articles freely available online

High visibility within the field

- Retaining the copyright to your article

Submit your next manuscript at $\boldsymbol{\nabla}$ springeropen.com 